\title{
The Bonding Ability and Bonding Site of a New Ferrocene Based Silicon Compound in Composite Solid Propellants
}

\author{
K. KISHORE and P. RAJALINGAM, Department of Inorganic and \\ Physical Chemistry Indian Institute of Science Bangalore-560 012 India
}

\section{INTRODUCTION}

Ammonium perchlorate (AP: 70-85 wt\%) and carboxy or hydroxy terminated polybutadiene (CTPB or HTPB: 15-20 wt\%) constitute the major ingredients of commonly-used composite solid propellant systems. The polymer, in addition to its function as a fuel, acts as a binder for the structural integrity of the solid propellant. Generally, the poor adhesion between the binder and oxidizer (AP) particles is improved by the use of bonding agents to achieve better mechanical properties. ${ }^{1}$ In spite of a number of bonding agents ${ }^{2-15}$ that have been used in the past, no attempt has been made to investigate the mechanism of bonding and the nature of the bonding site(s) in the molecule. Recently, we have reported a new ferrocene compound 1,1'bis(glycidoxymethyl) ferrocene) which acts as a bonding agent. ${ }^{16}$ In the present investigation, we have synthesized a new ferrocene-based silicon compound (I) and studied its bonding behavior in the AP-HTPB propellant system. This compound will have the additional advantage of being a burning rate modifier as well as an energy supplier. ${ }^{17-19}$ We have also attempted to locate the bonding site in the above molecule.

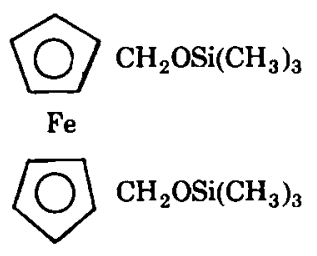

\section{EXPERIMENTAL}

\section{Hydroxy Terminated Polybutadiene (HTPB)}

Hycar HTBN (BF Goodrich) was vacuum dried and used.

\section{Synthesis of Compounds}

(a) 1,1'-bis(trimethylsilaxymethyl) ferrocene (BTMF. I): 1,1'-bis(hydroxymethyl) ferrocene, the starting material, was prepared and characterized as reported elsewhere. ${ }^{20,21}$ Trimethylchlorosilane $(1 \mathrm{~mol})$ in dry ether $(4 \mathrm{~mol})$ was added dropwise to $1,1^{\prime}$-bis(hydroxymethyl) ferrocene $(1 \mathrm{~mol})$ and dry pyridine $(1 \mathrm{~mol})$ in ether $(50 \mathrm{~mol})$ at $0-5^{\circ} \mathrm{C}$. The mixture was stirred at that temperature for about $12 \mathrm{~h}$. The precipitated pyridine hydrochloride was filtered. The filtrate was repeatedly washed with water and dried 
over $\mathrm{Na}_{2} \mathrm{SO}_{4}$. On evaporation of the ether, a low melting solid, 1, $1^{\prime}$-bis(trimethylsiloxymethyl) ferrocene was obtained. (b.p. $114-115^{\circ} \mathrm{C} / 0.3 \mathrm{~mm}$, yield-78\%).

${ }^{1} \mathrm{H} \mathrm{NMR} \mathrm{CDCl}_{3}: \delta 0.12\left(\mathrm{~S}, 18 \mathrm{H}\right.$, trimethylsilyl); $4.13\left(\mathrm{~S}, 4 \mathrm{H}, \mathrm{CH}_{2}\right) ; 4.42(\mathrm{~S}, 8 \mathrm{H}$, ferrocene).

IR $\left(\mathrm{CCl}_{4}\right): 3100(m), 2960(s), 1990(w), 1700(w), 1380(m), 1260(s), 1010(s), 840$ $(m), 660(m), 520(s) \mathrm{cm}^{-1}$.

(b) 1,1'bis(methaxymethyl) ferrocene: Though the synthesis of this compound is reported, ${ }^{22}$ we have adopted the following new procedure for its synthesis. $1,1^{\prime}$-bis(hydroxymethyl) ferrocene $(0.02 \mathrm{~mol})$ was dissolved in sodium tert-butoxide (prepared from $9 \mathrm{~mL}$ of tert-butanol and $2.3 \mathrm{~g}$ of sodium). The mixture was vigorously stirred for about $90 \mathrm{~min}$ at room temperature, and $6.3 \mathrm{~g}$ of dimethyl sulphate was added and the reaction was continued for another $10 \mathrm{~min}$. The reaction mixture was diluted with water $(75 \mathrm{~mL})$ and the oily layer extracted with ether, which was further washed with water, dried over $\mathrm{Na}_{2} \mathrm{SO}_{4}$, and distilled under reduced pressure after the removal of ether (b.p. $105-106^{\circ} \mathrm{C} / 0.2 \mathrm{~mm}$, yield-85\%). ${ }^{1} \mathrm{H}$ NMR data and b.p. agree with the reported values. ${ }^{22}$

${ }^{1} \mathrm{H}$ NMR $\mathrm{CDCl}_{3}: \delta 3.22\left(\mathrm{~S}, 6 \mathrm{H}, \mathrm{CH}_{3}\right) ; 4.06\left(\mathrm{~S}, 4 \mathrm{H}, \mathrm{CH}_{2}\right) ; 3.91(\mathrm{~S}, 8 \mathrm{H}$, ferrocene). IR (neat): $3150(s), 3000(s), 2615(m), 2110(w), 1700(w), 1490(m), 1395(s), 1250$ $(w), 1200(s), 980(s) \mathrm{cm}^{-1}$.

(c) Benzyltrimethylsilyl ether: This compound was prepared by the procedure followed by Gerrard and Kilburn. ${ }^{23}$ The spectral data of this compound have not been reported earlier.

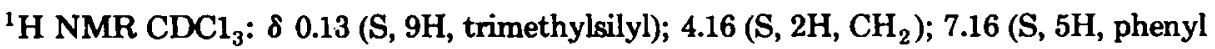
ring)

(d) Benzylmethyl ether: Though the synthesis of this compound is reproted, ${ }^{24}$ we have adopted a different procedure as given below. A solution of benzyl chloride $(0.04$ $\mathrm{mol})$ in sodium methoxide $(0.05 \mathrm{~mol})$ was refluxed with stirring for about $2 \mathrm{~h}$. The mixture was diluted with water $(50 \mathrm{~mL})$ and extracted with ether. The ethereal layer was washed in succession with water, sodium hydroxide ( $5 \%$ solution), and finally with water and dried over $\mathrm{Na}_{2} \mathrm{SO}_{4}$. Evaporation of the solvent ether gave the benzylmethyl ether boiling at $175-176^{\circ} \mathrm{C}$ (yield-87\%).

${ }^{1} \mathrm{H}$ NMR $\mathrm{CDCl}_{3}: \delta 3.06\left(\mathrm{~S}, 3 \mathrm{H}, \mathrm{CH}_{3}\right) ; 4.16\left(\mathrm{~S}, 2 \mathrm{H}, \mathrm{CH}_{2}\right) ; 7.00(\mathrm{~S}, 5 \mathrm{H}$, phenyl ring). IR (neat): $3110(m), 2990(s), 1960(m), 1840(w), 1740(s), 1620(s), 1440(s), 1100$ (s), $700(w) \mathrm{cm}^{-1}$.

\section{Solubility Measurements}

The solubility experiments were done as described elsewhere. ${ }^{16,25}$ The HTPB (2 g) and the bonding compounds (nil, $0.01 \mathrm{M}$ or $0.02 \mathrm{M}$ ) in $100 \mathrm{~mL}$ dry carbon tetrachloride were placed in a $150-\mathrm{mL}$ stoppered conical flask. The mixture was stirred at a constant speed and at different intervals of time; $2 \mathrm{~mL}$ portions were pippetted into previously weighed $5 \mathrm{~mL}$ beakers. The solvent was removed by evaporation and reweighed. The amount of HTPB dissolved at various intervals of time was calculated. The solubility measurements were also done with AP-HTPB system; AP particles were first coated with a bond agent and subsequently mixed with HTPB (AP-5 g, HTPB-2 g, CCl ${ }_{4} 100$ $\mathrm{mL}$ ). The experiments were repeated as before and the solubility of HTPB was determined. The solubility data are presented in Tables I and II. 


\section{Infrared (IR) Spectra}

IR spectra were recorded on a Perkin Elmer Model 597IR spectrophotometer using a $\mathrm{KBr}$ pellet.

\section{RESULTS AND DISCUSSION}

The solubility of HTPB in the presence or absence of the bonding agent, BTMF, is shown in Table I. Higher solubility of HTPB represents its bonding ability with the bonding agent; BTMF is therefore a good bonding agent for HTPB as it increases the solubility by about $3 \%$. Solubility of HTPB in the presence of some model compounds (Table I, columns 3, 4, and 5) was studied such that the role of the most probable active bonding centers (viz. the ferrocene center and silicon center in BTMF) could be located. The molar concentration of the compounds in column 3 and 4 were taken as double to those of ferrocene compounds (columns 5 and 6) because they have two identical side chains in the same molecule. Comparisons of the solubilities in columns 3 and 4 and columns 5 and 6 give the effect of the silicon center on the bonding ability of BTMF with HTPB; the presence of silicon center increases the solubility by $3-4 \%$. Comparisons of the solubility of HTPB in columns 3 and 5 and 4 and 6 give the bonding effect at the ferrocene centre. No significant difference in the solubility of HTPB is observed, suggesting that the bonding does not occur at the ferrocene center.

The results presented in Table II show the bonding ability of BTMF, both with AP and HTPB which is representative of the real propellant situation. A similar analysis as discussed above shows that the silicon center (columns 3 and 4 and 5 and 6 ) is the most active site; the difference in the HTPB solubility is about $6 \%$ which is almost double compared to that of HTPB-BTMF system (Table I). This goes to show that the silicon center is the bonding site for both HTPB and AP to an equal extent. Here again the ferrocene center (columns 3 and 5 and 4 and 6) does not exhibit any bonding property.

In order to get further insight into the bonding site in BTMF, IR spectra of BTMF, $\mathrm{AP}$, and $\mathrm{BTMF}+\mathrm{AP}$ (1:1 by weight mixture) were recorded in $\mathrm{KBr}$ (Fig. 1). The $-\mathrm{Si}$ $-\mathrm{CH}_{3}$ stretching vibration peaks in BTMF in the mixture shifts from $1250 \mathrm{~cm}^{-1}$ to

TABLE I

Solubility of HTPB In $\mathrm{CCl}_{4}$ in the Presence and Absence of Bonding Compounds at $28^{\circ} \mathrm{C}$

\begin{tabular}{|c|c|c|c|c|c|}
\hline \multirow[b]{2}{*}{$\begin{array}{l}\text { Time } \\
\text { (min.) }\end{array}$} & \multicolumn{5}{|c|}{ Percentage solubility of HTPB in $\mathrm{CCl}_{4}(100 \mathrm{ml})$} \\
\hline & HTPB (2g) & $\begin{array}{c}\mathrm{HTPB}(2 \mathrm{~g})+ \\
\mathrm{PhCH}_{2} \mathrm{OCH}_{3} \\
(0.02 \mathrm{M})\end{array}$ & $\begin{array}{c}\mathrm{HTPB}(2 \mathrm{~g})+ \\
\mathrm{PhCH}_{2} \mathrm{OSi}- \\
\left(\mathrm{CH}_{3}\right)_{3} \\
(0.02 \mathrm{M})\end{array}$ & $\begin{array}{l}\mathrm{HTPB}(2 \mathrm{~g})+ \\
\widehat{\mathrm{Fe}} \mathrm{CH}_{2} \mathrm{OCH} \\
\mathrm{CH}_{2} \mathrm{OCH}_{3} \\
(0.01 \mathrm{M})\end{array}$ & $\begin{array}{l}\mathrm{HTPB}(2 \mathrm{~g})+ \\
\text { e) } \mathrm{CH}_{2} \mathrm{OSi}\left(\mathrm{CH}_{3}\right)_{3} \\
\mathrm{CH}_{2} \mathrm{OSi}\left(\mathrm{CH}_{3}\right)_{3} \\
(0.01 \mathrm{M})\end{array}$ \\
\hline 1 & 39.7 & 40.1 & 45.1 & 40.3 & 43.7 \\
\hline 3 & 59.9 & 60.6 & 66.0 & 61.2 & 65.1 \\
\hline 5 & 72.1 & 72.9 & 78.3 & 73.0 & 76.6 \\
\hline 7 & 83.2 & 83.0 & 86.2 & 82.6 & 85.2 \\
\hline 10 & 96.3 & 96.5 & 98.0 & 96.9 & 97.2 \\
\hline
\end{tabular}




\section{TABLE II}

Solubility of $\mathrm{HTPB}$ and $\mathrm{AP}$ in $\mathrm{CCl}_{4}$ at $28^{\circ} \mathrm{C}$

\begin{tabular}{|c|c|c|c|c|c|}
\hline \multirow[b]{2}{*}{$\begin{array}{l}\text { Time } \\
\text { (min.) }\end{array}$} & \multicolumn{5}{|c|}{ Percentage solubility of $\mathrm{HTPB}$ in $\mathrm{CCl}_{4}(100 \mathrm{ml})$} \\
\hline & $\begin{array}{l}\mathrm{AP}(5 \mathrm{~g})+ \\
\operatorname{HTPB}(2 \mathrm{~g})\end{array}$ & $\begin{array}{c}\mathrm{AP}(5 \mathrm{~g})+ \\
\mathrm{HTPB}(2 \mathrm{~g})+ \\
\mathrm{PhCH}_{2} \mathrm{OCH}_{3} \\
(0.02 \mathrm{M})\end{array}$ & $\begin{array}{c}\mathrm{AP}(5 \mathrm{~g})+ \\
\mathrm{HTPB}(2 \mathrm{~g})+ \\
\mathrm{PhCH} 2 \mathrm{OSi}- \\
\left(\mathrm{CH}_{3}\right)_{3}\end{array}$ & $\begin{array}{l}\mathrm{AP}(5 \mathrm{~g})+ \\
\mathrm{HTPB}(2 \mathrm{~g})+ \\
\widehat{\mathrm{Fe}} \mathrm{CH}_{2} \mathrm{OCH} \\
\mathrm{CH}_{2} \mathrm{OCH} \\
(0.01 \mathrm{M})\end{array}$ & $\begin{array}{l}\mathrm{AP}(5 \mathrm{~g})+ \\
\mathrm{HTPB}(2 \mathrm{~g})+ \\
\mathrm{CH}_{2} \mathrm{OSi}\left(\mathrm{CH}_{3}\right)_{3} \\
\mathrm{CH}_{2} \mathrm{OSi}\left(\mathrm{CH}_{3}\right)_{3} \\
(0.01 \mathrm{M})\end{array}$ \\
\hline 25 & 34.0 & 34.4 & 40.5 & 34.7 & 40.7 \\
\hline 40 & 53.4 & 54.7 & 62.1 & 54.5 & 61.6 \\
\hline 50 & 64.1 & 64.9 & 73.5 & 63.9 & 73.1 \\
\hline 70 & 82.2 & 81.5 & 87.0 & 82.1 & 87.2 \\
\hline 85 & 91.0 & 91.7 & 95.1 & 91.5 & 95.2 \\
\hline
\end{tabular}

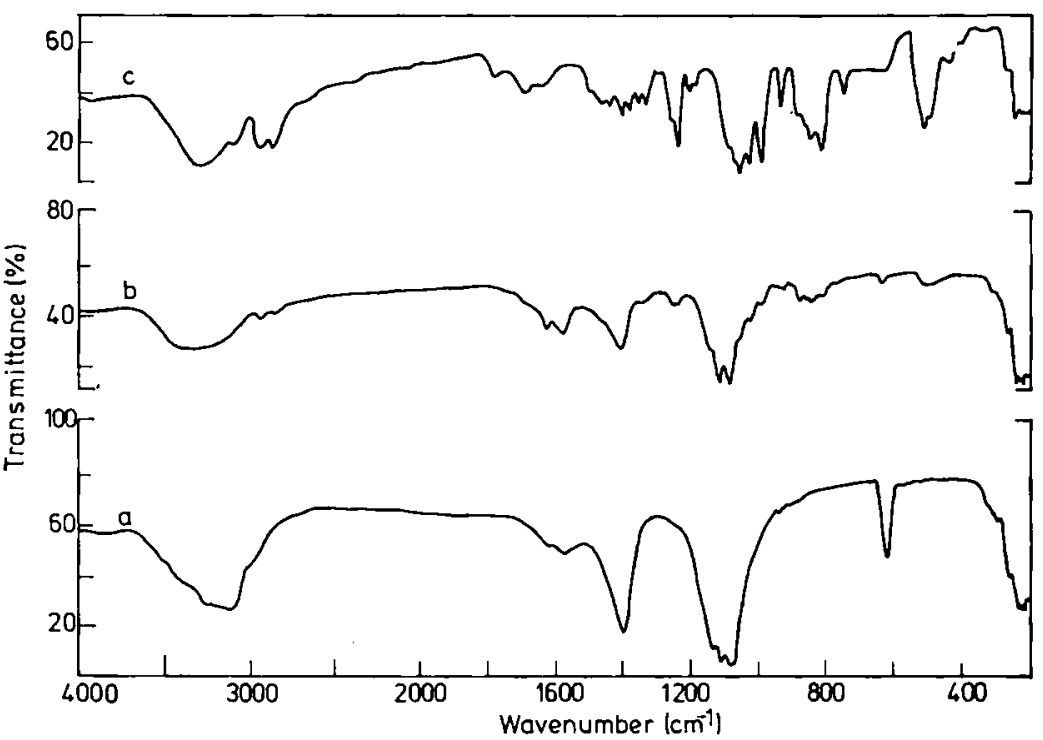

Fig. 1. IR spectra of (a) ammonium perchlorate (b) ammonium perchlorate + BTMF (1:1 mixture) and (c) BTMF in KBr Pellet.

$1230 \mathrm{~cm}^{-1}$, indicating that the $-\mathrm{Si}\left(\mathrm{CH}_{3}\right)_{3}$ group is involved in bonding. There is no change in the methyl $-\mathrm{C}-\mathrm{H}$ stretching vibrations $\left(2930 \mathrm{~cm}^{-1}\right)$, which explains that bonding does not take place through methyl groups and therefore it occurs at the silicon center. As the $-\mathrm{N}-\mathrm{H}$ bending in AP and the $-\mathrm{C}-\mathrm{H}$ bonding in BTMF are in the same region, there is less passibility of assigning the peaks for bending vibrations of $-\mathrm{C}-\mathrm{H}$. The $\mathrm{ClO}_{4}^{-}$bending peak $\left(620 \mathrm{~cm}^{-1}\right)$ shifts to $605 \mathrm{~cm}^{-1}$, indicating that $\mathrm{ClO}_{4}^{-}$in AP are involved in bonding. Thus, AP and BTMF interact through $\mathrm{ClO}_{4}^{-}$and silicon center, respectively. The bonding of BTMF with AP and HTPB can be illustrated as follows. 


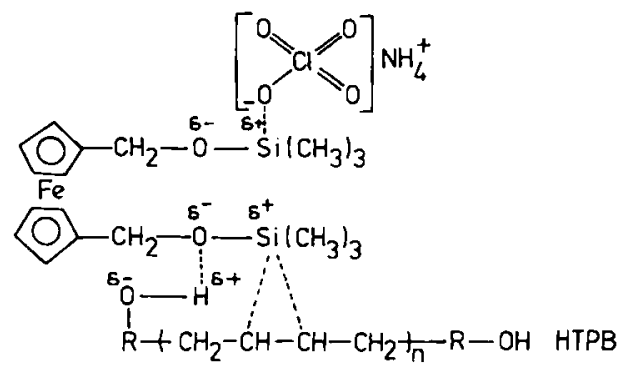

The above results undoubtedly show that the bonding of BTMF with both AP and HTPB occurs at the silicon center.

It is shown from the present work that the BTMF having a silicon center is a good bonding agent, but the similar ferrocene compound (namely $1,1^{\prime}$-bis(methoxymethyl) ferrocene) without a silicon center, does not act as a bonding agent. On the other hand, the non-ferrocene compound having a silicon center, benzyltrimethylsilylether, is as good a bonding agent as BTMF. It is well known that ferrocene compounds are generally used for their multifunctional characteristics like burning rate modifier and a bonding agent. Invariably mast of the ferrocene compounds are good burning rate modifiers but few of them could function as a bonding agent provided they contain some active sites in the molecule for interaction with AP and the binder. BTMF is undoubtedly such an interesting compound, which is a potential bonding agent in addition to its role as a burning rate modifier. Further, the silicon center in BTMF not only acts as a bonding site but also functions as an energy supplier during combustion.

In other works many ferrocene compounds have been claimed as a bonding agent. ${ }^{11,14-16}$ The present investigation shows that the ferrocene center does not offer any bonding site; the other active centers in such ferrocene compounds may have to be looked into for the bonding behavior like the one shown in BTMF.

\section{CONCLUSIONS}

A new compound, 1,1'-bis(trimethylsiloxymethyl) ferrocene, has been synthesized and is found to be a good bonding agent for the AP-HTPB system. In comparison with identical molecules, it is observed that the silicon centre is the active bonding site in the above compound.

The authors are thankful to Aero. Res. and Develop. Board, Ministry of Defense, New Delhi, for financial support. Encouragement by Dr. K. R. K. Rao, Director, E.R.D.L., Pune, is gratefully acknowledged.

\section{References}

1. A. C. Eringen, H. Liebowitz, S. L. Kho, and J. M. Crowley, Eds., Mechanics and Chemistry of solid Propellants Proc. 4th Symp. Naval Structural Mechanics, Pergamon, New York. 1967.

2. J. L. Boivin, Can. J. Chem., 36, 1405 (1968).

3. L. J. Bornstein, U.S. Patent 3,535,174 (1970).

4. R. Dick, G. Mavel, and F. R. Mankowshi, Colloq. Int. C.N.R.S., 231, 165 (1975).

5. H. R. Schloss, Recent Advances in Adhesion Proceedings, Am. Chem. Soc. Symp. No. 485, Am. Chem. Soc., Washington D.C., 1971.

6. S. K. Nema, P. R. Nair, A. V. Francis, and V. R. Gowrikar, AIAA J. 77, 932 (1977).

7. J. Linsk, U.S. Patent 3,056,702 (1962).

8. M. T. Cucksee and H. C. Allen, U.S. Patent 4,070,213 (1978).

9. T. R. Rudy, T. W. Nakagawa, and I. M. Greendorfer, U.S. Patent, 3,480,488 (1969). 
10. K. K. Thaper, Y. P. Saradhy, and V. K. Jain, Combust. Flame, 29, 325 (1977).

11. W. F. Arendale, U.S. Patent 4,023,994 (1977).

12. D. C. Van Landuyt and O. E. Ayers, U. S. Patent 3,765,965 (1973).

13. D. C. Van Landuyt and O. E. Orval, U.S. Patent $3,925,410$ (1975).

14. J. R. Mackey and E. T. Foster, U. S. Patent 4,070,212 (1978).

15. R. C. Corley and F. M. Dewey, U. S. Patent, 3,874,957 (1975).

16. K. Kishore, V. R. Pai Verneker, and G. Varghese Dharmaraj, J. Polym. Sci., Polym. Lett. Ed., 22, 607 (1984).

17. C. Markin and H. L. Williams, J. Appl. Polym. Sci., 18, 21 (1974).

18. B. B. Lanpert, U.S. Patent 3,984,264 (1976).

19. H. H. Ender, U.S. Patent 3,190,775 (1965).

20. M. Rosenblum and R. B. Woodward, J. Am. Chem. Soc., 80, 5443 (1958).

21. A. Sonoda and I. Moritani, J. Organometal, Chem., 26, 133 (1971).

22. P. L. Pauson, M. A. Sandhu, and W. E. Watts, J. Chem. Soc., (C) 251 (1966).

23. W. Gerrard and K. D. Kilburn, J. Chem. Soc., 1536 (1956).

24. Rolf Huisgen and Hans Reimlinger, Ann., 599, 183 (1956).

25. D. L. Granatstein and H. L. Williams, J. Appl. Polym. Sci., 18, 1 (1979).

Received December 16, 1985

Accepted April 7, 1986 